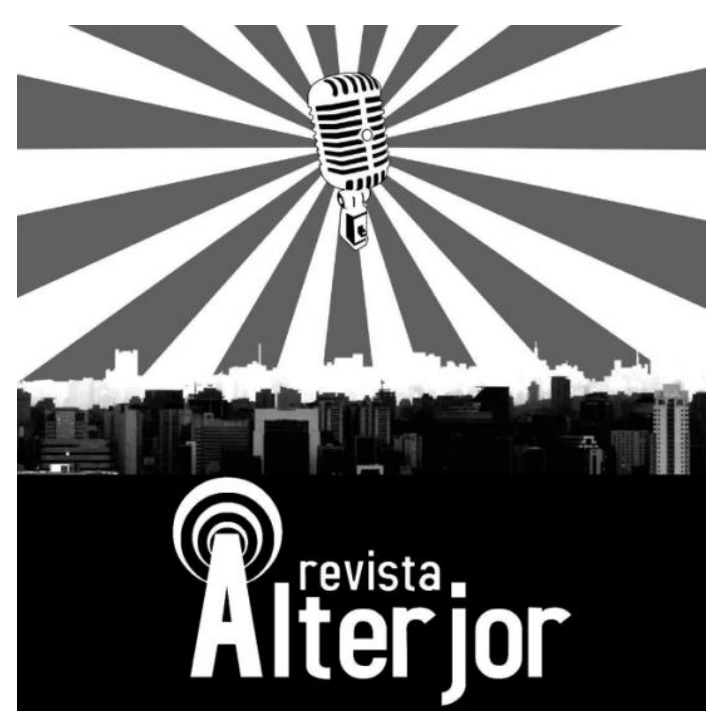

\title{
A DESERTIFICAÇÃO MIDIÁTICO-ESPORTIVA DO MATO GROSSO DO SUL: PRIMEIRÁS ANÁLISES E REFLEXÕES SOBRE A COBERTURA JORNALÍSTICA DO ESPORTE LOCAL
}

\author{
Breno Brey D'auria ${ }^{1}$ \\ Marina Brasiliano Salerno ${ }^{2}$ \\ Silvan Menezes dos Santos ${ }^{3}$
}

RESUMO: O objetivo do estudo foi compreender como a construção noticiosa sobre esporte no Mato Grosso do Sul contribui para o processo de desertificação midiático-esportiva da região. Recolhemos notícias de três portais de notícias do estado durante os Jogos Pan-americanos e Jogos Parapanamericanos de 2019. Mapeamos 77 notícias relacionadas ao primeiro e 21 notícias referentes ao segundo evento. Codificamo-las e submetemos para leitura pelo programa estatístico Iramuteq, com complemento analítico sobre autoria e enquadramento das notícias. A partir das análises, observamos $65,7 \%$ das notícias com replicação de conteúdos de agências e 78,6\% delas com enquadramento nacional ou global. Notamos, então, a tendência de desertificação midiático-esportiva da região, muito influenciada pelo subdesenvolvimento esportivo local.

PALAVRAS-CHAVE: Mídia. Esporte. Jornalismo esportivo. Mídia regional. Enquadramento.

ABSTRACT: The objective of the study was to understand how the news construction about sport in Mato Grosso do Sul contributes to the process of media-sports desertification in the region. We collected news from three state news portals during the Pan American and Parapan American Games in 2019. We map 77 news related to the first and 21 news related to the second event. We coded them and the data analysis was performed with Iramuteq statistical program, with an analytical complement on the authorship and framing of the news. From the analysis, we observed $65.7 \%$ of news with replication of content from agencies and $78.6 \%$ of them with national or global framework. We noticed, then, the trend of media-sports desertification in the region, which was very influenced by the local underdevelopment of sports.

KEYWORDS: Media. sport. Sports journalism. Regional media. Framing.

\footnotetext{
Professor de Educação Física, estudante do curso de Licenciatura em Educação Física pela Universidade Federal de Mato Grosso do Sul. Pesquisador do Remix - Observatório de mídias, tecnologias digitais e práticas corporais.E-mail: b_brey@ hotmail.com

Professora Doutora do Curso de Educação Física, Universidade Federal de Mato Grosso do Sul. E-mail: marina.brasiliano@ufms.br

${ }^{3}$ Professor adjunto dos cursos de Educação Física da Faculdade de Educação da Universidade Federal de Mato Grosso do Sul Coordenador do Remix - Observatório de mídias, tecnologias digitais e práticas corporais. E-mail: silvan.menezes@ufms.br
}

\section{Revista ALTERJOR}

Grupo de Estudos Alterjor: Jornalismo Popular e Alternativo (ECA-USP)

Ano 10 Volume ol Edição $23 \quad$ Janeiro-Julho de 2021

Avenida Professor Lúcio Martins Rodrig̉ues, 443, Cidade Universitária, São Paulo, CEP: 05508-020 


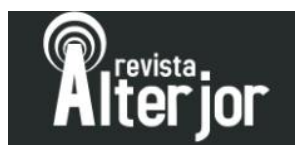

\section{INTRODUÇÃO}

O contexto da globalização econômica nos possibilitou a identificação do caráter heterogêneo do fenômeno esportivo, em especial pelas diferentes formas de os diversos povos percebê-lo, organizá-lo e praticá-lo (MARQUES; GUTIERREZ; MONTAGNER, 2009; MARQUES; ALMEIDA; GUTIERREZ, 2007; MARQUES, 2015). No que se refere à comunicação de massa, observamos formarem-se conglomerados midiáticos que potencializaram o processo de mundialização da cultura, produzindo e transmutando bens culturais em produtos transnacionais, massificando-os e nos massificando, não sendo diferente com a produção midiático-esportiva (MORAES, 1998; PIRES, 2002; SPÀ, 1999; 2007).

As transformações comunicativas e culturais da globalização, ainda em andamento, também têm deixado os impactos para com os veículos de mídia local ou regional, bem como para o trabalho jornalístico nestas dimensões territoriais (PERUZZO, 2005). Por exemplo, expandiu-se a produção noticiosa baseada em agências de notícias nestes contextos, o que foi, segundo Wolf (1987), de suma importância para o provimento da internacionalização da informação e da conexão noticiosa do mundo, fomentando a apresentação de contextos distantes e distintos para os diversificados povos. Todavia, para o autor houve também uma distorção informativa que a produção noticiosa agenciada causou, pois resumiu a narrativa jornalística ao factual, aos acontecimentos previstos e, por vezes, imprevistos.

As informações e notícias sobre as localidades têm grande relevância para o desenvolvimento local e regional (SILVA et al., 2017). Elas possuem caráter emancipatório, pois podem servir ao esclarecimento da sociedade sobre a qual se referem e, portanto, ao exercício da cidadania. Apesar disso, no Brasil tem-se identificado um processo chamado de desertificação do noticiário local. Segundo classificação do Atlas da Notícia ${ }^{4}$, existem $62 \%$ de municípios brasileiros desertos de notícias locais (sem nenhum veículo jornalístico local) e outros 19\% quase-desertos (com 1 ou 2 meio de informação local). O Mato Grosso do Sul (MS), região onde

\footnotetext{
${ }^{4}$ Atlas da Notícia (https://www.atlas.jor.br/). Acesso em 25 de março de 2020. 


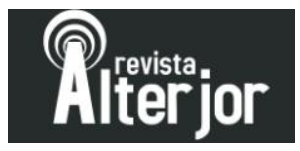

desenvolvemos o presente estudo, é um dos estados com os menores índices de desertos e quase-desertos de notícias. Nele, pouco mais de 50\% dos municípios são considerados desertos informativos.

Diante do cenário descrito, em especial de globalização midiático-esportiva, importa saber: Como tem se organizado e produzido o jornalismo esportivo local frente a tal processo de desertificação midiática? Nesse sentido, o objetivo do estudo foi compreender como a construção noticiosa sobre esporte no Mato Grosso do Sul contribui para o processo de desertificação midiático-esportiva da região.

\section{PERCURSO E ESTRATÉGIAS METODOLÓGICAS}

Desenvolvemos este estudo como uma análise de produto midiático (PIRES; LAZZAROTTI FILHO; LISBOA, 2012), em perspectiva descritiva e exploratória (MARQUES et al., 2017), com abordagem quanti-qualitativa dos dados. Recolhemos notícias de três portais de notícias do estado (Correio do Estado ${ }^{5}$, Campo Grande News ${ }^{6}$ e Mídiamax ${ }^{7}$ ), durante os Jogos Pan-americanos e Jogos Parapan-americanos de 2019. Coletamo-las no período de uma semana antes dos eventos até uma semana após o encerramento de ambos. Mapeamos 77 notícias relacionadas ao primeiro e 21 notícias referentes ao segundo.

No primeiro procedimento analítico, identificamos a autoria das notícias de modo a verificar a proporção de produção jornalística esportiva local e de reprodução de notícias advindas de agências. Também analisamos os enquadramentos noticiosos da cobertura dos três portais, classificando-os em três enfoques (local, nacional ou global). Além disso, verificamos a associação entre as duas variáveis, autoria e enquadramento.

$\mathrm{Na}$ segunda estratégia metodológica de análise, organizamos e codificamos o conteúdo dos dados textuais das notícias no programa OpenOffice Writer.

\footnotetext{
${ }^{5}$ https://correiodoestado.com.br/. Acesso em 28 de outubro de 2020.

${ }^{6}$ https://www.campograndenews.com.br/. Acesso em 28 de outubro de 2020.

${ }^{7}$ https://www.midiamax.com.br/. Acesso em 28 de outubro de 2020.
} 
Posteriormente, os submetemos para a leitura pelo programa Iramuteq (RATINAUD, 2009).

A tabulação dos dados envolveu a elaboração de corpus textuais separados, um específico do Pan-americano e outro do Parapan-americanos. Depois disso realizamos as análises de classificação pelo método Reinert, com a apresentação da classificação hierárquica descendente (CHD) para cada corpus textual. Tal análise apresenta os principais vocábulos separados por classes, demonstrando os elementos que se destacam dentro dos critérios estabelecidos sendo $\left[\chi^{2}(1) \geq 3,84, p<0,01\right]$, bem como os principais discursos.

Os segmentos de texto foram classificados de acordo com seus vocábulos e o conjunto resultante foi dividido com base na frequência das formas reduzidas, desenvolvidas a partir do radical das palavras (lemmatisation), formando-se classes para as quais se baseiam as análises (CAMARGO; JUSTO, 2013). As classes são nomeadas a partir da interpretação dos dados obtidos, sendo que para a presente pesquisa os autores realizaram o estudo das classes individualmente para minimizar discrepâncias. De modo complementar, utilizou-se a nuvem de palavras gerada a partir dos dois corpus textuais como mais um elemento ilustrativo das análises empreendidas.

\section{APRESENTAÇÃO DOS ACHADOS DA PESQUISA}

Nesta seção do trabalho apresentamos os dados recolhidos nos portais de notícias sul-mato-grossenses no período referente aos Jogos Pan e Parapan-americanos de 2019, conforme detalhado anteriormente. Em primeiro lugar destacamos os resultados relacionados à autoria e aos enquadramentos das publicações dos veículos de mídia e, na sequência, os dados do conteúdo noticioso propriamente dito.

\section{Autoria e enquadramento da cobertura jornalística do Pan e Parapan de 2019 nos portais de notícias sul-mato-grossenses}

Do total de 98 notícias mapeadas no estudo, 65,7\% delas foram replicações de conteúdos informativos advindos de agências de notícias e 34,3\% notícias assinadas por

\footnotetext{
Revista AL TERJOR

Grupo de Estudos Alterjor:Jornalismo Popular e Alternativo (ECA-USP)

Ano 10 Volume ol Edição $23 \quad$ Janeiro-Junho de 2021

Avenida Professor Lúcio Martins Rodriģues, 443, Cidade Universitária, São Paulo, CEP: 05508-020
} 


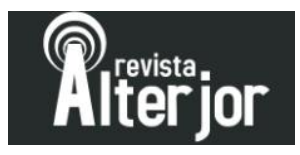

jornalistas locais dos portais investigados. Ressaltamos, conforme tabelas 1 e 2 a seguir, que a cobertura do primeiro megaevento esportivo obteve maior proporção de produção jornalística agenciada em comparação com o evento de esporte para pessoas com deficiência.

Tabela 1. Assinatura das notícias na cobertura jornalística dos Jogos Pan-Americanos 2019

\begin{tabular}{|c|c|c|c|}
\hline \multicolumn{2}{|c|}{ Jornalistas Locais } & \multicolumn{2}{c|}{ Agências } \\
\hline Nome & $\%$ & Nome & $\%$ \\
\hline Rafael Ribeiro & 14,1 & Agência Brasil & 37,2 \\
\hline Gabriel Neris & 10,3 & Estadão Conteúdo & 26,9 \\
\hline Clayton Neves & 1,3 & Agência Estado & 3,8 \\
\hline Leonardo Rocha & 1,3 & Globoesporte.com & 1,3 \\
\hline Jones Mário & 1,3 & - & - \\
\hline Diego Alves & 1,3 & - & - \\
\hline TOTAL & $\mathbf{2 9 , 6}$ & TOTAL & $\mathbf{6 9 , 2}$ \\
\hline
\end{tabular}

Fonte: produção dos autores.

Tabela 2. Assinatura das notícias na cobertura jornalística dos Jogos Parapan-Americanos 2019

\begin{tabular}{|c|c|c|c|}
\hline \multicolumn{2}{|c|}{ Jornalistas Locais } & \multicolumn{2}{c|}{ Agências } \\
\hline Nome & $\%$ & Nome & \% \\
\hline Rafael Ribeiro & 14,3 & Agência Brasil & 47,6 \\
\hline Diego Alves & 9,5 & Estadão Conteúdo & 4,8 \\
\hline Gabriel Neris & 9,5 & - & - \\
\hline Ana Palma & 4,8 & - & - \\
\hline Vinicius Costa & 4,8 & - & - \\
\hline Leonardo Rocha & 4,8 & - & - \\
\hline TOTAL & $\mathbf{4 7 , 7}$ & TOTAL & $\mathbf{5 2 , 4}$ \\
\hline
\end{tabular}

Fonte: produção dos autores.

Ao associarmos a autoria das notícias com os enquadramentos midiáticos destinados aos megaeventos esportivos, na cobertura do Parapan identificamos relação 


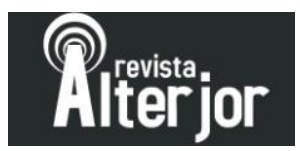

direta entre as notícias advindas de agências e os enquadres nacionais ou globais, bem como as publicações assinadas por jornalistas locais se ativeram a elementos e personagens esportivos vinculados à região. Diferentemente, a cobertura do Pan pelos portais sul-mato-grossenses confirmou parcialmente a tendência de relação entre as variáveis, pois $96,3 \%$ das notícias advindas de agências possuem enquadramento nacional, mas as notícias produzidas por jornalistas locais, por outro lado, estiveram divididas entre enquadramentos da localidade e da nacionalidade brasileira, sendo $47,8 \%$ e $52,2 \%$ de cada um deles, respectivamente.

Tabela 3. Associação entre autoria das notícias e enquadramento noticioso na cobertura do PanAmericano 2019

\begin{tabular}{|c|c|c|}
\hline \multirow{2}{*}{ Enquadramento } & \multicolumn{2}{|c|}{ Mídia } \\
\cline { 2 - 3 } & 1 - Local & 2 - Agência \\
\cline { 2 - 3 } & $\mathbf{n}(\%)$ & $\mathbf{n}(\%)$ \\
\hline 1 - Local & $11(47,8)$ & $1(1,8)$ \\
\hline 2 - Nacional & $12(52,2)$ & $52(96,3)$ \\
\hline 3 - Global & $0(0)$ & $1(1,8)$ \\
\hline
\end{tabular}

Fonte: produção dos autores.

Tabela 4. Associação entre autoria das notícias e enquadramento noticioso na cobertura do ParapanAmericano 2019

\begin{tabular}{|c|c|c|}
\hline \multirow{2}{*}{ Enquadramento } & \multicolumn{2}{|c|}{ Mídia } \\
\cline { 2 - 3 } & 1 - Local & 2 - Agência \\
\cline { 2 - 3 } & $\mathbf{n}(\%)$ & $\mathbf{n}(\%)$ \\
\hline 1 - Local & $9(90)$ & 0 \\
\hline 2 - Nacional & $1(10)$ & $10(90,9)$ \\
\hline 3 - Global & 0 & $1(9,1)$ \\
\hline
\end{tabular}

Fonte: produção dos autores.

\section{Dados do conteúdo jornalístico gerados pelo Iramuteq}

Para o presente tópico apresentaremos os resultados obtidos a partir do corpus textual extraído das notícias. 


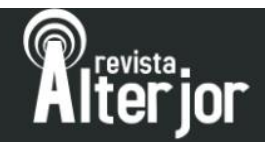

Pan-americano

O corpus analisado sobre o Pan-americano foi constituído por 789 segmentos de texto (ST). Destacaram-se uma média de 34,41 número de palavras com radicais distintos por segmentos de textos, com um total de 27.142 ocorrências (total de palavras contidas no corpus). A divisão total foi realizada em 712 ST, o que representou 90,27\% do total do corpus classificado na análise. Inicialmente, realizamos a CHD, que permitiu identificar quatro classes distintas, as quais foram denominadas de acordo com seus descritores mais representativos.

Figura 1. Dendograma da CHD - PAN-AMERICANO

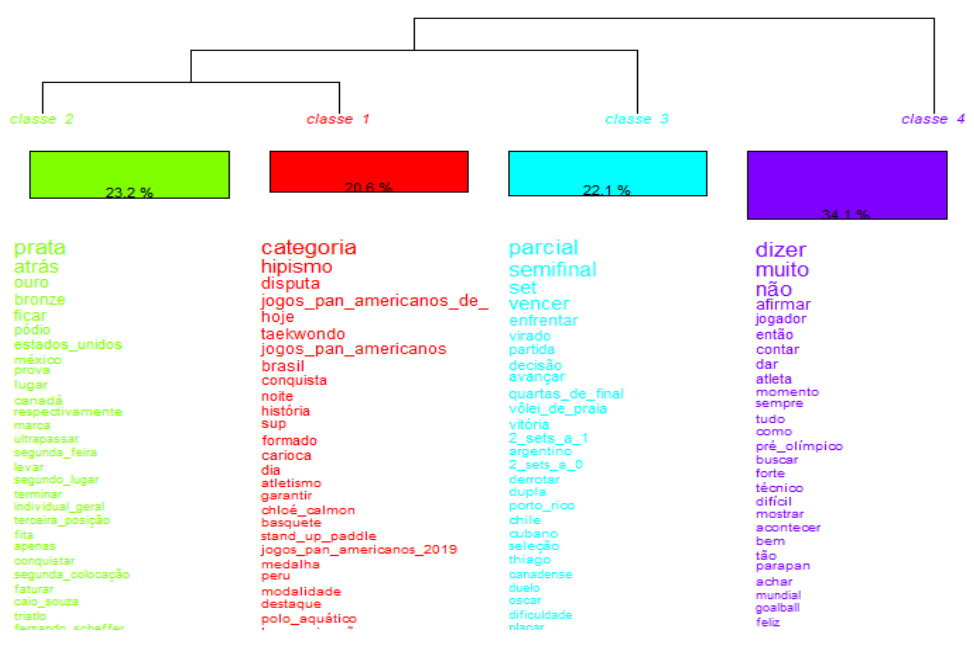

A classe 1PAN $\left(\mathrm{ST}_{\text {Classe1 }}=147\right.$, que explica $20,65 \%$ do total $)$ foi denominada rotina competitiva nas modalidades, e apresentou elementos voltados aos atletas e conquistas em suas modalidades e a evolução dentro do evento. (e.g., hipismo, disputa, história, conquista, Chloé Calmon, Stand up Paddle).

“[...] com 9 medalhas conquistadas Biekarck é o mais velho da equipe, dois anos mais novo o velejador Gunnar Ficker, 64, também está na disputa pelo pódio no encontro de gerações do time Brasil também estão duas atletas de 15 anos a esgrimista Victória Vizeu e a Bia Mantellato do polo aquático".

A classe 2PAN $\left(\mathrm{ST}_{\text {Classe } 2}=165\right.$, que explica $23,71 \%$ do total $)$ foi denominada de resultados e medalhas, e apresentou aspectos referentes aos resultados alcançados pelos atletas e pelos países em diferentes modalidades esportivas ao longo do evento (e.g., 


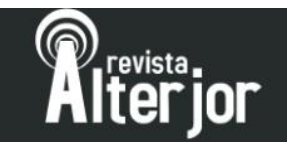

prata, pódio, Canadá, ginástica rítmica, Chico Barreto). Observamos, então, a ênfase na performance dos atletas e modalidades a partir dos resultados obtidos, como destacamos nos trechos a seguir:

"[...] a modalidade amealhou 10 ouros nas últimas 3 edições do Pan, Rio de Janeiro, Guadalajara e Toronto. Entre os favoritos nas provas rápidas de nado livre estão Bruno Fratus, líder do ranking mundial nos 50m, Marcelo Chierighini 100m e Fernando Scheffer 200m".

A classe 3PAN $\left(\mathrm{ST}_{\text {Classe } 3}=157\right.$, que explica $22,05 \%$ do total $)$ foi denominada de trajetória e desempenho brasileiro, com enfoque para o feminino, e trouxe o processo que levou à vitória, derrota ou empate (e.g., parcial, semifinal, decisão, derrotar).

“[...] mas o patinador ainda pode conseguir medalha de ouro hoje na final dos $10.000 \mathrm{~m}$ masculino, corrida pelo bronze a equipe brasileira feminina de espada composta por Nathalie Moellhausen, Victória Vizeu e Amanda Simeão venceu hoje o méxico nas quartas de final e vai enfrentar Cuba na disputa pelo bronze"

A classe 4PAN $\left(\mathrm{ST}_{\text {Classe4 }}=243\right.$, que explica $34,13 \%$ do total $)$ foi denominada de relatos de experiência e sensações esportivas dos atletas, e destacou trajetórias de competições, suas participações e planejamento para participação em outros eventos competitivos (e.g., pré-olímpico, momento, atleta).

“[...] o técnico Marcelo Fronckowiak fez questão de elogiar a atuação do adversário deste sábado: Nós jogamos contra a seleção principal de Cuba enquanto a seleção brasileira tem um grupo jovem diante dessa realidade que enfrentamos de ter o pré-olímpico quase ao mesmo tempo do pan".

\section{Parapan-americano}

O corpus analisado sobre o Parapan-americano foi constituído por 234 segmentos de texto (ST). Destacou-se uma média de 34,94 número de palavras com radicais distintos por segmentos de textos, com um total de 8.178 ocorrências (total de palavras contidas no corpus). A divisão total foi realizada em 183 ST, o que representou $78,21 \%$ do total do corpus classificado na análise. Inicialmente, realizamos a CHD, que 


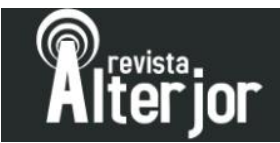

permitiu identificar seis classes distintas, definidas de acordo com seus descritores mais representativos, conforme apresentadas a partir da Figura 2 abaixo.

Figura 2. Dendograma da CHD - PARAPAN-AMERICANO

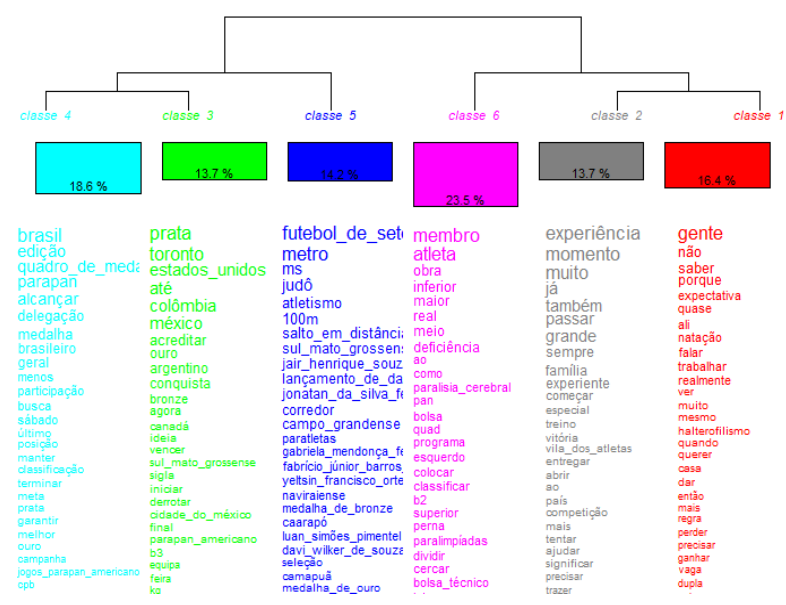

A classe 1PARA $\left(\mathrm{ST}_{\text {Classe } 1}=30\right.$, que explica $16,39 \%$ do total $)$ foi denominada expectativa pelo resultado do trabalho, e apresentou elementos voltados à espera dos atletas por bons resultados dentro da competição, advindos do trabalho e da dedicação ao treinamento (e.g., expectativa, trabalhar, saber, porque).

“[...] mas mesmo assim eu estou com uma expectativa muito grande de que a gente vai ultrapassar aquelas 109 de toronto na manhã de hoje a nadadora Cecília Araújo já deu mais uma contribuição".

A classe 2PARA ( $\mathrm{ST}_{\text {Classe2 }}=25$, que explica $13,66 \%$ do total) foi denominada grandeza desta experiência esportiva, com indicadores de percepção dos atletas sobre a participação em evento internacional, bem como momentos pessoais que podem afetar a participação na competição (e.g., experiência, momento, passar, grande).

“[...] quando comecei não tinha essa base é importante passar nossa experiência, pois em pouco tempo eles irão assumir a camisa da seleção principal e esse parapan já é uma porta de entrada para muitos que chegam agora." 


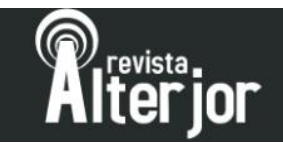

A classe 3PARA $\left(\mathrm{ST}_{\text {Classe3 }}=25\right.$, que explica $13,66 \%$ do total $)$ foi denominada crença no resultado positivo a partir da história recente, e contém elementos de relações com edições anteriores dos Jogos Parapan-americanos ou de outros eventos, como as paralimpíadas escolares (e.g., acreditar, prata, Toronto, ouro).

“[...] ele chegou à seleção em 2013 e hoje é campeão mundial bronze paralímpico e conquistou o bicampeonato parapan-americano em Lima, parece impossível mas não é, acreditem nos seus sonhos, as paralimpíadas escolares foram as portas para tudo isso".

A classe 4PARA $\left(\mathrm{ST}_{\text {Classe4 }}=34\right.$, que explica $18,58 \%$ do total $)$ foi denominada panorama geral do Brasil no quadro de medalhas, e agrupou notícias referentes ao desempenho dos atletas, com apresentação dos resultados dos jogos de Lima e de edições anteriores (e.g., Brasil, edições, quadro de medalhas, delegação, medalha).

“[...] jogos parapan-americanos, 2019, Brasil bate recorde e alcança melhor campanha da história em parapans, o Brasil encerrou os jogos de Lima no Peru com a melhor campanha de todos os tempos em parapan-americanos."

A classe 5PARA $\left(\mathrm{ST}_{\text {Classe5 }}=26\right.$, que explica $14,21 \%$ do total) foi denominada Representação e atuação da localidade (MS e municípios) na competição, e apresentou referência aos atletas do estado de Mato Grosso do Sul, com destaque nominal aos atletas, bem como indicativo de suas modalidades e conquistas (e.g., futebol de sete, Mato Grosso do Sul (MS), judô, atletismo, campo grandense).

“[...] nascido em Campo Grande, Davi Wilker de Souza conquistou o bronze nos 400 metros, de Caarapó, Jonatan da Silva Ferreira conquistou o bronze nos 100 metros, os atletas de MS, Hebert Honório Lemes Oviedo, Heitor Luiz Ramires Camposano, Leonardo Giovani Morais e Wesley Gabriel dos Santos Ferreira compuseram a seleção de futebol de sete que conquistou o ouro no parapan-americanos."

A classe 6PARA ( $\mathrm{ST}_{\text {Classe6 }}=43$, que explica $23,5 \%$ do total) foi denominada $A$ deficiência dos atletas e a acessibilidade estrutural da cidade sede, e compilou notícias que explicaram especificidades das modalidades adaptadas e de condições de 


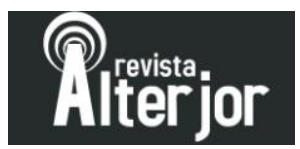

deficiência dos atletas, bem como aquelas que indicaram particularidades da acessibilidade da cidade sede (e.g., membro, atleta, obra, inferir).

“[...] já na categoria quad ${ }^{8}$ além da lesão nos membros inferiores os atletas têm alguma deficiência nos membros superiores a principal diferença em relação ao tênis tradicional é que no tênis em cadeira de rodas a bola pode quicar duas vezes sendo que o segundo quique pode ser fora da quadra”.

\section{DISCUSSÃO}

Os dados das autorias das notícias e dos enquadramentos identificados no estudo indicam uma tendência de desertificação da produção noticiosa sobre o esporte local. Tal cenário se deve, sobretudo, pela proporção de $65 \%$ da cobertura ter sido feita por meio de notícias advindas de agências e, juntamente a isso, pelo fato de somente $21,4 \%$ do noticiário ter sido construído com enquadramentos sobre a localidade.

Importante frisar que o fenômeno da desertificação aqui apontado, está para além daqueles $50 \%$ de municípios do estado que se configuram como desertos ou quase-desertos de notícias. Nestes casos do nosso estudo, os veículos locais existem, mas os produtos noticiosos veiculados por eles são rarefeitos na opção jornalística de enquadrar a localidade, ou melhor, na decisão de não a enquadrar prioritariamente. Isso pode estar associado às condições profissionais das redações das mídias analisadas, como por exemplo o contingente de jornalistas suficientes para colocar (ou não) as questões esportivas locais em maior evidência, com mais espaço em seus respectivos portais ${ }^{9}$.

A cobertura do Parapan realizada pelos mesmos veículos, em contraponto ao cenário desértico descrito, nos revelou que quando houve maior volume de participação

\footnotetext{
${ }^{8}$ Nomenclatura utilizada no tênis em cadeira de rodas para indicar atleta com comprometimento motor nos membros inferiores e no membro superior que utiliza para o jogo.

${ }^{9}$ Wolf (1987), quando fala das rotinas produtivas e se refere ao trabalho com as agências destaca o modelo agenciado de produzir, reproduzir e veicular recortes das diferentes realidades dado, principalmente, pelo custo-benefício de contratá-las, que normalmente é melhor do que distribuir enviados especiais para as distintas regiões do mundo.
} 


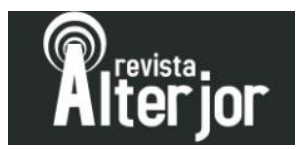

e de potencial esportivo de atletas da região ${ }^{10}$, foi possível dedicar maior atenção e espaço midiático para a localidade. Enquanto os portais analisados, na produção noticiosa sobre o Pan, dedicaram 15,6\% do espaço para informações sobre o esporte estadual, no caso do Parapan essa proporção subiu para 42,8\%, compondo quase metade do volume total de notícias sobre a competição, mesmo com um número menor de notícias. A relação dessa tendência com o maior número de representantes locais no evento para atletas com deficiência se reforça ao observarmos a existência da classe 5PARA. Em contraponto, não existe nenhuma classe de relevância sobre atletas locais nas notícias do Pan.

Os dados nos revelam, portanto, que a mídia precisa da existência de atletas locais competitivos em nível internacional para mobilizar o valor-notícia da proximidade $^{11}$ ou, por exemplo, a estratégia da dialética global-local ${ }^{12}$. Diante disso, compreendemos existir não só um processo de desertificação midiática estadual, mas também uma desertificação midiático-esportiva na região. Quando o contexto local se mostrou um pouco mais desenvolvido esportivamente, ele angariou mais espaço na produção jornalística. Ou seja, considerando a relação simbiótica entre mídia e esporte (SPÀ, 1999; 2007), os dados indicam para a necessidade de o polo esportivo e seus agentes invistirem no desenvolvimento e expansão do esporte na localidade de modo a gerar subsídios para que tal fenômeno se transforme em notícia no jornalismo local.

A dependência midiática das personalidades esportivas locais se expõe não só na territorialidade dos enquadramentos. Ela é delineada também na composição textual das notícias veiculadas pelos três portais. A centralidade da figura do atleta na cobertura do

\footnotetext{
${ }^{10}$ Segundo dados do Comitê Olímpico Brasileiro e do Comitê Paralímpico Brasileiro, para os Jogos Panamericanos foram convocados 485 atletas brasileiros, sendo quatro do MS. Para os Jogos Parapanamericanos, por sua vez, foram 337 atletas na delegação brasileira, sendo 12 do MS.

${ }^{11}$ A proximidade é um importante critério de noticiabilidade para os veículos jornalísticos locais e regionais, justamente porque são subsidiados pelo vínculo contextual entre leitores e desdobramentos do cotidiano, seja um contexto de dimensão geográfica ou simbólica (FERNANDES, 2014; TORRES NETO, 2017).

${ }^{12}$ Estratégia, comumente mobilizada pelo jornalismo esportivo, de vinculação da localidade com manifestações midiático-esportivas globais, tais como os Jogos Pan e Parapan-americanos, as Copas do Mundo de futebol masculino e os Jogos Olímpicos e Paralímpicos (PIRES et al., 2008; MEZZAROBA et al., 2009, 2015; RIBEIRO et al., 2009; SANTOS et al., 2016; BITENCOURT, 2005; PIRES, 2009).
} 


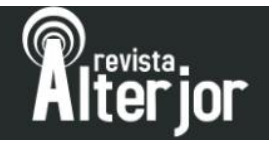

Parapan e, diferentemente, da imagem nacionalista no caso do Pan, podem ser visualizadas nas nuvens de palavras produzidas a partir de cada corpus textual submetido ao programa.

Figura 3. Nuvem de palavras construída a partir do corpus textual da cobertura jornalística dos Jogos PanAmericanos 2019.

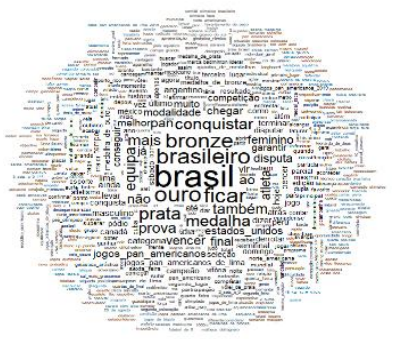

Figura 4. Nuvem de palavras construída a partir do corpus textual da cobertura jornalística dos Jogos Parapan-Americanos 2019.

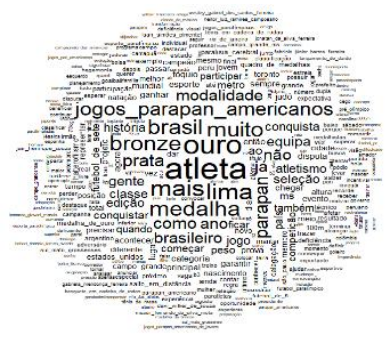

A personificação das notícias e os nacionalismos são tendências comumente identificadas em discursos midiático-esportivos, em diferentes contextos. A primeira estratégia é adotada como forma de explorar o mito do herói e do vilão (HELAL, 1998), ou como meio de construir representações de atletas como modelos de comportamento (SANTOS; MEDEIROS, 2009). A segunda é explorada, principalmente, como via de construção, associação e massificação de determinadas perspectivas ideológicas às imagens dos Estados-nação (PIRES, 1998; BRUCE, 2014).

No caso do nosso estudo, entretanto, os dados indicam que as abordagens da mídia local, nacionalista no Pan e personalista no Parapan, foram fortemente condicionadas pelo contexto esportivo local. A fragilidade e a sub-representação do esporte regional na primeira competição abriu espaço para uma cobertura jornalística concentrada nos quadros nacionais. Por sua vez, a potente e maior representação do 


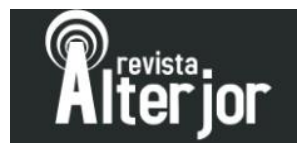

estado na segunda competição, possibilitou a construção de enquadres midiáticos localizados, compostos principalmente pelos atletas personalidades da região. Nesse sentido, tais dados reforçam a tese de que a desertificação noticiosa sobre o esporte da localidade em questão se deve muito ao subdesenvolvimento esportivo regional (especificamente no que se refere à dimensão do rendimento continental, que é o foco do presente estudo).

Outro ponto a ser destacado com base nas diferentes classes geradas pelo Iramuteq, é a de que não houve uma relação direta entre a amplitude da cobertura midiática com a quantidade de notícias. No caso específico do Parapan, em que mais classes foram identificadas, temos o indicativo de uma cobertura midiática mais abrangente, mais próxima da multidimensionalidade do fenômeno esportivo (MARCHI JUNIOR, 2016), mesmo com uma quantidade muito menor de notícias se comparado com a cobertura dos Jogos Pan-americanos.

As classes 1PAN (rotina competitiva nas modalidades), 2PAN (resultados $e$ medalhas), 3PAN (trajetória e desempenho brasileiro, com enfoque para o feminino), 1PARA (expectativa pelo resultado do trabalho), 3PARA (crença no resultado positivo a partir da história recente) e 4PARA (panorama geral do Brasil no quadro de medalhas), indicam para uma prática de reprodução do jornalismo esportivo local daquilo que, segundo Betti (2001), configura a rotina da falação esportiva. Tal como descreve o autor, os portais mapeados no presente estudo criaram expectativas sobre possíveis campeões, fizeram previsões e prometeram vitórias, bem como enfocaram o binômio vitória-derrota ao sobrevalorizarem, principalmente, os quadros de medalhas.

Em contraponto à tendência de caráter reprodutivo da mídia esportiva local, as classes 4PAN (relatos de experiência e sensações esportivas dos atletas) e 2PARA (grandeza desta experiência esportiva) apresentam-se como indicativo de uma cobertura jornalística voltada para a inteireza do esporte. Elas representam a busca dos veículos analisados por dar voz aos e às atletas, deixando-lhes falar sobre a "[...] experiência global de praticar esporte" (BETTI, 2001, p. 3). Ainda que sejam pequenas proporções das respectivas construções noticiosas, 34,13\% (4PAN) e 13,66\% (2PARA), dessa forma as mídias locais contribuem para a diversificação e expansão da cultura 


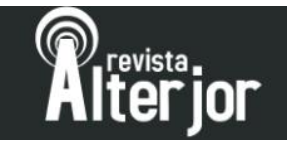

esportiva, e atendem ao primeiro dos itens do decálogo para uma cobertura esportiva responsável, que é a função pública do jornalismo e o direito à informação (ACCOUNTABLE SPORTS JOURNALISM, 2017).

Complementar aos fatores supracitados, a cobertura do Parapan, em especial na categoria 6PARA, denominada A deficiência dos atletas e a acessibilidade estrutural da cidade sede, apresenta um indicativo da lacuna de contextualização do esporte voltado à pessoa com deficiência na esfera local, principalmente referente à deficiência física e visual que se destacam no referido megaevento. Segundo guias de cobertura midiática do esporte para pessoas com deficiência, deve-se mencionar e enfocar as deficiências dos atletas apenas quando necessário para a melhor compreensão da competição (BRITISH PARALYMPIC ASSOCIATION, 2012; INTERNATIONAL PARALYMPIC COMMITTEE, 2014; PAPPOUS; SOUZA, 2016). Nesse sentido, ao enfocarem as deficiências dos atletas em parte relevante da cobertura do evento esportivo, as mídias sul-mato-grossenses analisadas reproduzem o modelo biomédico de compreendê-las, ou seja, centra-se nas suas características individuais e corporais como fatores explicativos das suas condições de vida. Entretanto, ao também abordarem questões estruturais de acessibilidade na cobertura esportiva, os respectivos portais mobilizam o modelo social de entendimento das deficiências, ou seja, apresentam os modos de organização da sociedade como parte determinante das barreiras e limitações que se impõem às pessoas em questão.

\section{CONSIDERAÇÕES FINAIS}

Os achados do presente estudo nos indicam uma tendência de desertificação midiático-esportiva do jornalismo sul-mato-grossense. Esse fenômeno se manifestou, sobretudo, na ocasião em que o contexto esportivo mostrou-se subdesenvolvido, como na baixa representatividade do esporte local nos Jogos Pan-americanos de 2019 em comparação com a situação nos Jogos Parapan-americanos do mesmo ano. A construção noticiosa analisada nos apresentou indicativos de que quando existiram mais elementos configurativos do critério de proximidade, especialmente a presença de atletas regionais 


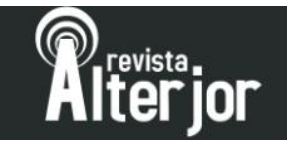

na competição continental, a mídia local dedicou mais tempo e espaço para que seus jornalistas produzissem e veiculassem notícias com enquadramentos voltados para a localidade.

O trabalho contribui, portanto, para visualizarmos que dificilmente existirá jornalismo esportivo local sem que haja políticas de desenvolvimento do esporte na respectiva localidade. Especificamente no caso sul-mato-grossense, observamos a necessidade de ampliação dos investimentos nas ações para desenvolver, principalmente, a prática esportiva convencional e seguir fomentando o esporte para pessoas com deficiência. Desse modo, evita-se o processo de desertificação midiáticoesportiva da região, bem como possibilita-se o reconhecimento, valorização e ampliação da cultura esportiva local.

\section{REFERÊNCIAS}

ACCOUNTABLE SPORTS JOURNALISM. Guidelines for covering sports responsibly. Accountable Sports Journalism, 2017. Disponível em: https://accountablesportsjournalism.org/code/. Acesso em: 23 jan. 2020

BETTI, M. Esporte na mídia ou esporte da mídia? Motrivivência, n. 17, p. 1-3, 2001.

BITENCOURT, F. G. et al. Ritual olímpico e os mitos da modernidade: implicações midiáticas na dialética universal-local. Pensar a prática, v. 8, n. 1, p. 2277-2277, 2005.

BRITISH PARALYMPIC ASSOCIATION. Guide to Reporting on Paralympic Sport. Reino Unido: ParalympicsGB, 2012. Disponível em: http://paralympics.org.uk/uploads/documents/imported/ParalympicsGB_Guide_to_Rep orting_on_Paralympic_Sport_-_June_2012.pdf. Acesso em 22 out. 2020

BRUCE, T. Us and them: the influence of discourses of nationalism on media coverage of the Paralympics. Disability \& Society, v. 29, n. 9, p. 1443-1459, 2014.

CAMARGO B, JUSTO AM. IRAMUTEQ: um software gratuito para análise de dados textuais. Temas em Psicologia, Ribeirão Preto, v. 21, n. 2, p. 513-518, dez. 2013. Disponível em: http://pepsic.bvsalud.org/scielo.php?script=sci_arttext\&pid=S1413389X2013000200016\&lng=pt\&nrm=iso. Acesso em: 4 out. 2017.

FERNANDES, M. L. A proximidade como critério de noticiabilidade: a força da notícia local. In: SILVA, G.; SILVA, M. P. DA; FERNANDES, M. L. (Eds.). Critérios de noticiabilidade: problemas conceituais e aplicações. Florianópolis: Insular, 2014. p. $139-156$. 


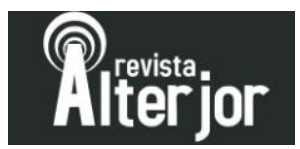

HELAL, R. Mídia, a construção da derrota e o mito do herói. Motus corporis, v. 5, n. 2, p. 141-155, 1998.

INTERNATIONAL PARALYMPIC COMMITTEE. Guide to reporting on persons with an impairment. Bonn: International Paralympic Committee, 2014. Disponível em:

https://www.paralympic.org/sites/default/files/document/141027103527844_2014_10_3 1+Guide+to+reporting+on+persons+with+an+impairment.pdf. Acesso em 22 out. 2020

MARCHI JUNIOR, W. O esporte "em cena": perspectivas históricas e interpretações conceituais para a construção de um Modelo Analítico. The journal of the Latin American socio-cultural studies of sport (ALESDE), v. 5, n. 1, p. 46-67, 2016.

MARQUES, H. R. et al. Metodologia da pesquisa e do trabalho científico. 5. ed. Campo Grande: UCDB, 2017.

MARQUES, R. F. R. O conceito de esporte como fenômeno globalizado: pluralidade e controvérsias. Revista Observatório del deporte, v. 1, n. 1, p. 147-185, 2015.

MARQUES, R. F. R.; ALMEIDA, M. A. B. DE; GUTIERREZ, G. L. Esporte: um fenômeno heterogêneo: estudo sobre o esporte e suas manifestações na sociedade contemporânea. Movimento (ESEF/UFRGS), v. 13, n. 3, p. p.225-242, 2007.

MARQUES, R. F. R.; GUTIERREZ, G. L.; MONTAGNER, P. C. Novas configurações socioeconômicas do esporte na era da globalização. Revista da Educação Física/UEM, v. 20, n. 4, p. 637-648, 2009.

MEZZAROBA, C. et al. Jogos Pan-Americanos Rio / 2007 : os “ locais " na mídia regional. Descrição e análise da cobertura em jornais das cinco regiões brasileiras. In: PIRES, G. D. L. (Ed.). “Observando” o Pan Rio/2007 na mídia. Florianópolis: Tribo da Ilha, 2009. p. 29-45.

MEZZAROBA, C. et al. O papel da mídia sergipana nas estratégias de agendamento na mobilização da dialética global-local a partir de uma situação concreta: as Olimpíadas / 2012. Motrivivência, v. 27, n. 44, p. 64-78, 2015.

MORAES, D. De. O planeta mídia: tendências da comunicação na era global. Campo Grande: Letra Livre, 1998.

PAPPOUS, A.; SOUZA, D. L. DE. Guia para a mídia: Como cobrir os Jogos Paralímpicos Rio 2016. Brasília: University of Kent / Universidade Federal do Paraná, 2016. Disponível em:

http://www.cpb.org.br/documents/20181/0/Guia+para+a+mídia+Rio+2016/a26cb8131e28-4e71-84d8-bd93ea39308c. Acesso em 22 out. 2020

Revista ALTERJOR

Grupo de Estudos Alterjor: Jornalismo Popular e Alternativo (ECA-USP)

Ano 10 Volume Ol Edição 23 Janeiro-Junho de 202l

Avenida Professor Lúcio Martins Rodrig̉ues, 443, Cidade Universitária, São Paulo, CEP: 05508-020 


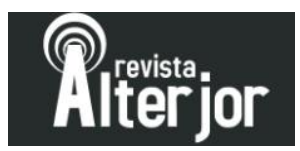

PERUZZO, C. M. K. Mídia regional e local: aspectos conceituais e tendências.

Comunicação \& Sociedade, v. 26, n. 43, p. 67-84, 2005.

PIRES, G. D. L. Breve introdução ao estudo dos processos de apropriação social do fenômeno esporte. Revista de Educação Física/UEM, v. 9, n. 1, p. 25-34, 1998.

PIRES, G. D. L. A Educação Física e o discurso midiático: abordagem críticoemancipatória. Ijuí: Unijuí, 2002.

PIRES, G. D. L. Introdução. In: PIRES, G. D. L. (Org.). "Observando" o Pan Rio2007 na mídia. Florianópolis: Tribo de Ilha, 2009, p. 15-26.

PIRES, G. D. L. et al. Jogos Olímpicos e a Dialética Global-Local : os Catarinenses em Atenas / 2004 na Mídia impressa regional. In: SANFELICE, G.; MYSKIW, M. (Eds.). Mídia e Esporte: Temas Contemporâneos. Novo Hamburgo: Feevale, 2008. p. 65-90.

PIRES, G. D. L.; LAZZAROTTI FILHO, A.; LISBÔA, M. M. Educação Física, mídia e tecnologias - Incursões, pesquisa e perspectivas. Kinesis, v. 30, n. 1, p. 55-79, 2012.

RATINAUD P. IRAMUTEQ: Interface de R pour les Analyses Multidimensionnelles de Textes et de Questionnaires [Computer software], 2009. http://www.iramuteq.org/

RIBEIRO, S. D. D. et al. Os atletas sergipanos em debate: análise da cobertura jornalística do Pan Rio-2007. In: PIRES, G. D. L. (Ed.). “Observando" o Pan Rio/2007 na mídia. Florianópolis: Tribo da Ilha, 2009. p. 129-148.

SANTOS, S. M. DOS et al. “DAY AFTER ”: o adeus aos Jogos Olímpicos de Londres / 2012 e as boas vindas ao Rio / 2016. Lúdica Pedagógica, v. 20, n. 20, p. 117-135, 2016.

SANTOS, D. S.; MEDEIROS, A. G. O discurso midiático e as representações sociais do esporte: o atleta como modelo de comportamento. Pensar a prática, v. 12, n. 3, p. $1-11,2009$.

SANTOS, S. M. dos; MEZZAROBA, C.; SOUZA, D. L. de. Jornalismo esportivo e Infotenimento: a (possível) sobreposição do entretenimento à informação no conteúdo jornalístico do esporte. Corpoconsciência, v. 21, n. 2, p. 93-106, 2017.

SILVA, R. DOS S. et al. Critérios de Noticiabilidade, Valores-Notícia e Jornalismo de Proximidade para o Desenvolvimento Regional/Local. $40^{\circ}$ Congresso Brasileiro de Ciências da Comunicação. Anais...Curitiba-PR: Intercom - Revista Brasileira de Ciências da Comunicação, 2017.

SPÀ, M. DE M. Comunicación y deporte en la era digital: sinergias, contradicciones y responsabilidades educativas. Contratexto, v. 12, p. 73-92, 1999.

Revista ALTERJOR

Grupo de Estudos Alterjor:Jornalismo Popular e Alternativo (ECA-USP)

Ano 10 Volume Ol Edição 23 Janeiro-Junho de 202l

Avenida Professor Lúcio Martins Rodrig̉ues, 443, Cidade Universitária, São Paulo, CEP: 05508-020 


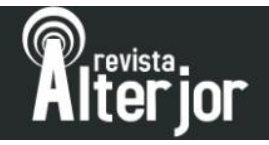

SPÀ, M. DE M. Comunicación y deporte en la era digital. (Asociación Española de Investigación Social Aplicada al Deporte, Ed.)IX Congreso de la Asociación Española de Investigación Social Aplicada al Deporte (AEISAD). Anais...Las Palmas de Gran Canaria: Centre d'Estudis Olímpics UAB, 2007. Disponível em: http://olympicstudies.uab.es/pdf/wp107_spa.pdf

TORRES NETO, A. P. A seca vira notícia: a proximidade como critério de noticiabilidade no jornalismo regional. $15^{\circ}$ Encontro Nacional de Pesquisadores em Jornalismo. Anais...São Paulo: SBPJor - Associação Brasileira de Pesquisadores em Jornalismo, 2017.

WOLF, M. La investigación de la comunicación de masas: crítica y perspectivas. Barcelona: Ediciones Paidós Ibérica, 1987. 